\title{
HUBUNGAN TINGKAT KECEMASAN DENGAN MEKANISME KOPING PADA PASIEN GAGAL GINJAL KRONIK YANG MENJALANI HEMODIALISA DI RUANGAN HEMODIALISA RUMAH SAKIT GRANDMED LUBUK PAKAM
}

\author{
Sari Desi Esta Ulina Sitepu ${ }^{\mathbf{1}}$, Ade viaulina ${ }^{2}$, Selamat Tuahta Sipayung ${ }^{\mathbf{3}}$, Pratiwi \\ Christa Simarmata ${ }^{4}$, Junita Ika Susanti br Ginting ${ }^{5}$ \\ $1,2,4,5$ Institut Kesehatan Medistra Lubuk Pakam \\ ${ }^{3}$ Sekolah Tinggi Ilmu Kesehatan Murni Teguh \\ Jl. Sudirman No 38 Lubuk Pakam Kab.Deli Serdang, Sumatera Utara. \\ e-mail : sitepudesisari@gmail.com
}

DOI $10.35451 / j k f . v 3 i 2.521$

\begin{abstract}
Chronic renal failure is a disorder in which the body's ability renal function failed to maintain metabolism, fluid and electrolyte balance. Hemodialysis is a process used patients in a state of acute illness requiring long-term therapy. The patients with renal failure often experience fear because of the conditions they experienced pain this can be a physical stressor that can lead patients to levels of stress and anxiety. Research design using cross- sectional. The population includes hemodialysis patients of Grandmed Hospital Lubuk Pakam. Samples consisting of 43 respondents meeting inclusion criteria were selected using purposive sampling method.This study presented based on the frequency and characteristics of respondents with results of the appointment that anxiety levels can be categorized as mild anxiety $(18,6 \%)$, moderate anxiety (41,9\%), and severe anxiety (39,5\%). For coping mechanisme of adaptive coping (39,5\%) and maladaptive coping (60,5\%) category. Analysis of this research data using chi-Square. The results showed that there was an association of anxiety level with coping mechanism in patients with chronic renal failure who underwent hemodialysis at Grandmed Hospital Lubuk Pakam with $p=0,031$. The more adaptive the respondent's clutch the lighter the level of anxiety experienced. The results of this study was expected to nurse or hemodialysis officers further improve the provision of counseling to patients hemodialysis so that patients are able use adaptive coping in the face of anxiety.
\end{abstract}

Keywords: Anxiety, Coping Mechanisms, Renal Failure, Hemodialysis.

\section{PENDAHULUAN}

Jumlah pasien yang menderita penyakit GGK (Gagal Ginjal Kronik) serta yang melakukan pengobatan hemodialisis di Indonesia mengalami peningkatan yang signifikan, berdasarkan survei yang telah dilaksanakan Perhimpunan Nefrologi
Indonesia (Wurara, Kanine \& Wowiling, 2013).

Fenomena yang dialami dan terjadi pada pasien selama pengobatan atau rutin terapi hemodialisis. Pada umumnya pasien mengalami kecemasan karena proses dialysis memerlukan waktu yang lama, dalam hal ini pasien ,memerlukan teknik 
Received: 11 Oktober 2020 :: Accepted: 29 April 2021 :: Published: 30 April 2021

penyelesaian masalah atau disebut dengan koping yang efektif dalam mengurangi dan mengatasi rasa cemas pasien. Seseorang mampu untuk mengatasi tekanan serta kecemasan melalui mobilisasi sumber koping dilingkungan seperti persediaan perekonomian, keahlian dalam menyelesaikan permasalahan, dukungan sosial dan kebudayaan (Stuart dalam dalam Taluta, Mulyadi \& Hamel, 2014).

Kecemasan ialah perasaan khawatir yang tidak jelas sebabnya serta tidak nyaman yang dirasakan oleh seseorang, rasa takut yang timbul akibat membayangkan bahaya yang akan terjadi(Andri, 2013).

Koping merupakan sebuah situasi dimana seseorang berupaya dalam mengatur ketidaksesuaian yang diperoleh antara yang diinginkan dengan yang diterima merupakan sebuah keadaan yang dipenuhi tekanan (Nasir \& Muhith,2011).

Mekanisme koping merupakan sebuah upaya yang dilakukan agar beradaptasi dengan tekanan atau stress (Saam \& Wahyuni dalam Taluta, Mlyadi \& Hamel, 2014). Gagal Ginjal Kronik (GGK) adalah permasalahan yang terjadi pada kerja ginjal yang progresif serta tidak bisa pulih, dimana tubuh tidak dapat menjaga proses metabolisme serta tidak bisa menjaga keseimbangan antara cairan dan elektrolit yang menyebabkan peningkatan ureum. Pasien Gagal Ginjal Kronis (GGK) memiliki karakteristik sifatnya menetap, tidak dapat disembuhkan dan membutuhkan pengobatan berupa, transplantation (pencangkokan) ginjal, dialisis peritoneal, hemodialisis dan rawat jalan dalam waktu yang cukup lama (Black, 2014).

Di Indonesia ditemukan sebanyak 18 juta orang yang mengalami sakit gagal ginjal kronik, pada tahun 2017 data Indonesia Renal Regetry tahun 2007 menunjukkan jumlah pasien yang menjalankan hemodialisis berjumlah 2148 penduduk sedangkan pada tahun 2018 jumlah pasien yang menjalankan hemodialisis bertambah yaitu menjadi 2260 penduduk. Berdasarkan data Dinkes Jatim sekitar 1 sampai 3 orang dari 10.000 penduduk menderita gagal ginjal kronik dan di wilayah Ponorogo lebih tinggi, 214 dari 10.000 penduduk mengalami gagal ginjal kronik.

\section{METODE PENELITIAN}

Jenis penelitian yang dipakai ialah penelitian kuantitatif dengan rancangan penelitian korelasional menggunakan Cross Sectional. Populasi dalam penelitan ini ialah semua pasien yang melakukan Hemodialisa yang akan menjadi objek penelitian serta memenuhi karakteristik yang telah ditentukan. Sampel untuk penelitian ini ialah pasien dengan penyakit Gagal Ginjal Kronik (GGK) yang melaksanakan pengobatan hemodialisa di ruangan hemodialisa di Rumah Sakit Grandmed Lubuk Pakam.

Dalam menghitung jumlah besar sampel apabila populasi tidak diketahui maka dapat menggunakan rumus Stanly Lemeshow:

$$
\begin{gathered}
n=\frac{Z_{1-\infty / 2}^{2}\left[P_{1}\left(1-P_{1}\right)+P_{2}-\left(1-P_{2}\right)\right]}{d^{2}} \\
n=\frac{(1,96)^{2}[0,5(1-0,5)+0,5-(1-0,5)]}{(0,15)^{2}} \\
n=42,67=43 \text { orang }
\end{gathered}
$$

Teknik pengambilan sample yang digunakan peneliti pada penelitian ini yaitu purposive sampling yaitu responden dipilih berdasarkan atas pertimbangan atau kriteria yang ditentukan oleh peneliti (Agus, 2017) kriteria-kriteria sampel pada penelitian ini yaitu :

a. Kriteria Inklusi:Pasien yang menjalani HD rutin 2 kali seminggu, Pasien dengan penyakit GGK, dan Pasien yang berusia 20-60 tahun. 
b. Kriteria Eksklusi :Pasien baru yang menjalani hemodialisa, dan Pasien komplikasi yang menjalani hemodialisa.

\section{HASIL}

\section{Tingkat Kecemasan Responden}

Berdasarkan dari hasil penelitian yang dilakukan pada 43 responden didapati frekuensi tingkat kecemasan yang dirasakan oleh pasien dengan sakit gagal ginjal kronik yang mengikuti hemodialisa. Pasien yang merasakan tingkat kecemasan sedang paling banyak yaitu berjumlah 18 orang $(41,9 \%)$.

Menurut Isaac dalam Tiedeman (2015) faktor yang mempengaruhi respon individu terhadap kecemasan antara individu dan individu lain dapat berbeda tergantung faktor-faktor seperti jenis kelamin, usia, tingkat pendidikan, status sosial/dukungan sosial, pekerjaan dan mekanisme koping.

\section{Mekanisme Koping Responden}

Berdasarkan hasil penelitian pada 43 responden dapat diketahui pasien dengan sakit gagal ginjal kronik yang melakukan terapi Hemodialisa di Rumah Sakit Grandmed Lubuk Pakam menunjukkan jumlah 26 orang $(60,5 \%)$ cenderung menggunakan mekanisme koping maladaptif.

Koping adalah respon seseorang terhadap keadaan yang membahayakan dirinya baik secara fisik ataupun psikologis. Faktor -faktor yang berpengaruh terhadap mekanisme koping seseorang yang pertama adalah umur.

Faktor yang kedua yaitu dukungan sosial. Dukungan sosial berperan untuk mencegah terjadi stres dan sudah diuji kebenarannya (Wills \& Filer Fegan, 2001) dalam Tiedeman (2015) bahwa dengan mempunyai kontak sosial yang banyak dapat melindugi sistem kekebalan tubuh seseorang terhadap stres.

\section{Hubungan Tingkat Kecemasan Dengan Mekanisme Koping Pada Pasien Gagal Ginjal Kronik yang menjalani Hemodialisa di Ruangan $\begin{array}{lll}\text { Hemodialisa Rumah } & \text { Sakit } \\ \text { Grandmed Lubuk Pakam } & \end{array}$}

Berdasarkan hasil penelitian dapat diketahui bahwa pasien dengan sakit Gagal Ginjal Kronik yang mengikuti terapi Hemodialisa di Ruangan Hemodialisa mayoritas cemas sedang dengan jumlah 18 orang responden $(41,9 \%)$ yang diantaranya 15 orang responden $\quad(34,9 \%) \quad$ memakai mekanisme koping maladaptif sedangkan cemas berat berjumlah 17 orang responden $(39,5 \%)$ dengan mekanisme koping maladaptif 7 orang responden ( $16,3 \%)$ dan mekanisme koping adaptif 10 orang responden $(23,2 \%)$.

Di sini terdapat bahwa responden yang mengalami cemas berat 17 orang responden tetapi 10 diantara memiliki koping adaptif dikarenakan koping adaptif diartikan bahwa seseorang memiliki pertahanan diri yang baik atau positif sehingga responden mampu berinteraksi dengan orang lain, relaksasi dalam menjalani hemodialisa dan yang membuat responden mengalami cemas berat karena proses penusukan pada vena dan arteri dan proses perjalanan hemodialisa yang pada saat hemodialisa darah dkeluarkan melalui blood line ke dializer yang menyebabkan sebagian besar responden lebih mengalami cemas berat karena takut, cemas melihat darah yang keluar tersebut dan petugas hemodialisa atau perawat hemodialisa kurang memberikan konseling terhadap pasien dengan sakit gagal ginjal kronik yang sedang mengikuti terapi hemodialisa.

Berdasarkan hasil uji chi square yang digunakan, maka didapatkan nilai 
$p=0,031<a=0,05$. Berarti ada hubungan tingkat kecemasan dengan mekanisme koping pada pasien Gagal Ginjal Kronik yang menjalani Hemodialisa di Ruangan Hemodialisa Rumah sakit Grandmed Lubuk Pakam.

\section{PEMBAHASAN}

\section{Tingkat Kecemasan Responden}

Kecemasan ialah perasaan dimana seseorang merasa tidak nyaman dan merasakan khawatir yang tidak jelas serta diikuti dengan respon outonom (pada umumnya penyebab tidak pasti dan jarang diketahui oleh seseorang), rasa takut yang timbul akibat membayangkan bahaya yang akan terjadi(Andri, 2013).

Menurut Isaac dalam Tiedeman (2015) faktor yang mempengaruhi respon individu terhadap kecemasan antara individu dan individu lain dapat berbeda tergantung faktor-faktor seperti tingkat pendidikan ,umur, jenis kelamin, status sosial/dukungan sosial, pekerjaan dan mekanisme koping.

Santrock (2017) mengatakan bahwa pendekatan secara psikologi pada perkembangan manusia mempengaruhi perbedaan kejiwaan antara laki-laki dan perempuan.

Berdasarkan hasil penelitian terhadap 43 responden didapati frekuensi tingkat kecemasan yang dirasakan oleh pasien dengan sakit gagal ginjal kronik yang mengikuti terapi hemodialisa. Pasien ataupun responden yang merasakan tingkat kecemasan sedang paling banyak yaitu berjumlah 18 orang $(41,9 \%)$.

$\mathrm{Hal}$ yang sedikit berbeda dikemukakan oleh Luana, dkk (2012) dimana tingkat kecemasan rata-rata pasien hemodialisa paling banyak dengan tingkat kecemasan ringan.

\section{Mekanisme Koping Responden}

Koping adalah respon seseorang terhadap keadaan yang membahayakan dirinya baik secara fisik ataupun psikologis.

Faktor -faktor yang berpengaruh terhadap mekanisme koping seseorang yang pertama adalah umur. Faktor yang kedua yaitu dukungan sosial. Dukungan sosial berperan sebagai pencegahan terjadinya stres dan telah diuji kebenarannya (Wills \& Filer Fegan, 2001) dalam Tiedeman (2015) bahwa dengan mempunyai kontak sosial yang banyak dapat melindugi sistem kekebalan tubuh seseorang terhadap stres.

Berdasarkan hasil penelitian pada 43 responden dapat diketahui pasien dengan penyakit gagal ginjal kronik yang mengikuti terapi Hemodialisa di Rumah Sakit Grandmed Lubuk Pakam menunjukkan jumlah 26 orang $(60,5 \%)$ cenderung memakai mekanisme koping maladaptif.

Taylor (2005) mengatakan bahwa penyebab seseorang menggunakan mekanisme koping maladaptif dikarenakan ; merasa tidak mampu, tidak bisa menyelesaikan permasalahan, merasa lemas, tegang, takut, gangguan fisiologis dan tidak dapat memenuhi kebutuhan dasar.

\section{Hubungan Tingkat Kecemasan Dengan Mekanisme Koping Pada Pasien Gagal Ginjal Kronik yang menjalani Hemodialisa di Ruangan Hemodialisa Rumah Sakit Grandmed Lubuk Pakam}

Berdasarkan hasil penelitian dapat diketahui bahwa pasien Gagal Ginjal Kronik yang menjalani Hemodialisa di Ruangan Hemodialisa mayoritas cemas sedang dengan jumlah 18 orang responden $(41,9 \%)$ yang diantaranya 15 orang responden (34,9\%) mempergunakan mekanisme koping maladaptif sedangkan cemas berat berjumlah 17 orang responden $(39,5 \%)$ dengan mekanisme koping maladaptif 7 orang responden ( $16,3 \%)$ 
Received: 11 Oktober 2020 :: Accepted: 29 April 2021 :: Published: 30 April 2021

dan mekanisme koping adaptif 10 orang responden $(23,2 \%)$.

Berdasarkan hasil uji chi square yang digunakan, maka didapatkan nilai $p=0,031<a=0,05$. Berarti ada hubungan antara tingkat kecemasan dengan mekanisme koping pada pasien dengan sakit Gagal Ginjal Kronik yang mengikuti terapi Hemodialisa di Ruangan Hemodialisa Rumah sakit Grandmed Lubuk Pakam.

Berdasarkan hasil penelitian ini dan didukung hasil penelitian lain serta teori yang telah dijelaskan oleh ahli maka bisa dibuat kesimpulan bahwa kebanyakan dari pasien dengan sakit gagal ginjal kronik yang mengikuti terapi hemodialisa mengalami tingkat kecemasan yang sedang dan berat.

Kecemasan timbul karena responden menggunakan koping yang maladaptif seperti takut akan kehilangan pekerjaan, menutup diri dari lingkungan, kurangnya dukungan keluarga serta masalah yang dialami responden saat menjalani hemodialisa dan ketidaktahuan proses dari menjalani hemodialisa. Hasil penelitian ini sejalan dengan Stuart (2012) bahwa pasien dengan sakit Gagal Ginjal Kronik yang mengikuti terapi hemodialisa kurang dari enam bulan cendrung mengalami kecemasan sedang dan berat.

Pasien dengan sakit Gagal Ginjal Kronik yang mengikuti terapi hemodialisa sangat besar kemungkinan mengalami kecemasan dikarenakan bahwa lamanya proses hemodialisa yang bahkan sampai seumur hidup, kurang adekuatnya informasi dari tenaga kesehatan terkait prosedur hemodialisa maupun kecemasan akan keberhasilan proses hemodialisa saat ini. Hal ini menjadi penyebab stress yang meningkatkan rasa cemas terhadap pasien dengan sakit Gagal Ginjal Kronik.

\section{KESIMPULAN}

Hasil dari penelitian yang sudah dikerjakan di rumah sakit Granmed lubuk Pakam dapat diambil kesimpulan sebagai berikut:

a. Pasien dengan sakit gagal ginjal kronik yang mengikuti terapi hemodialisa sebagian besar terjadi pada perempuan. Dan untuk karakteristik umur responden terbanyak yang menjalani hemodialisa dengan gagal ginjal kronik adalah umur 41-60 tahun.

b. Tingkat kecemasan pasien dengan sakit gagal ginjal kronik yang mengikuti terapi Hemodialisa di Ruangan Hemodialisa Rumah Sakit Grandmed Lubuk Pakam, dari 43 orang responden mayoritas cemas sedang.

c. Mekanisme koping pasien dengan sakit Gagal Ginjal Kronik yang melakukan Hemodialisa di Ruangan Hemodialisa Rumah Sakit Grandmed Lubuk Pakam, dari 43 orang responden mayoritas mempunyai mekanisme koping maladaptif.

d. Ada hubungan tingkat kecemasan dengan mekanisme koping pada pasien Gagal Ginjal Kronik yang menjalani Hemodialisa di Ruangan Hemodialisa Rumah Sakit Grandmed Lubuk Pakam, dimana nilai $p=0,031<a=0,05$.

\section{DAFTAR PUSTAKA}

$\begin{array}{llr}\text { Agus, } & \begin{array}{c}\text { R. } \\ \text { METODOLOGI }\end{array} & \begin{array}{c}\text { APLIKASI } \\ \text { PENELITIAN } \\ \text { KESEHATAN. } \\ \text { Yogyakarta : } \\ \text { Nuha Medika }\end{array} \\ \text { Andri, } & \begin{array}{l}\text { (2013). TEORI } \\ \text { BERDASARKAN }\end{array} & \text { KECEMASAN } \\ & \text { PSIKOANALISIS } & \text { KLASIK DAN } \\ & \text { BERBAGAI } & \text { MEKANISME } \\ & \text { PERTAHANAN } & \text { TERHADAP }\end{array}$


Received: 11 Oktober 2020 :: Accepted: 29 April 2021 :: Published: 30 April 2021

KECEMASAN.

Majalah

Kedokteran Indonesia, Volume : 57,233 - 238.

Black, J M., dan Hawrks, H. (2014). KEPERAWATAN MEDIKAL BEDAH.(edisi 8. Buku2).

Luana, N.A., Panggabean,S., Lengkong, J.V.M, \& Christine. I (2012). KECEMASAN PADA PENDERITA PENYAKIT GINJAL KRONIK YANG MENJALANI HEMODIALISIS DI RS UNIVERSITAS KRISTEN INDONESIA. Media Medika Indonesia. 46(3)

Nasir abdul \& Muhith abdul (2011) DASAR - DASAR KEPERAWATAN JIWA. Jakarta, Salemba Medika, 2011.

Santrock, J.W (2017). PSIKOLOGI PENDIDIKAN Edisi Kedua. Jakarta : Kencana Prenada Media Group

Stuart, G.W (2012). PRINCIPLES AND PRACTICE OF PHYCHIATRIC NURSING. 9th ed. St. Louis: Mosby.

Taluta, Y. P., Mulyadi \& Hamel, R. S., 2014. HUBUNGAN TINGKAT KECEMASAN DENGAN MEKANISME KOPING PADA PENDERITA DIABETES MELITUSTIPE 2 DI POLIKLINIK PEYAKIT DALAM RUMAH SAKIT UMUM DAERAH TOBELO KABUPATEN HALMAHERA UTARA. Ejourna Ikeperawatan, 1(2), pp. 1-9.

Taylor. (2005). HEALTH PSYCHOLOGY. Fifth Edition. United States of America : McGraw-Hill, Inc

Tiedeman, (2015). MANAJEMEN STRESS. Edisi ke - 3. Jakarta: EGC.

Wurara, Y., Kanine, E., Wowiling, F. 2013. MEKANISME KOPING PADA PASIEN PENYAKIT GINJAL KRONIK YANG MENJALANI TERAPI
HEMODIALISI DI RS. PROF. DR. R.D KANDOU MANADO. 